remain in a reinforced area, or a combination of these.

When GB1 reinforcement is terminated, the performance of Group 3 in the start and run segments of RW2 increases. Notice, however, that the performance of this downshifted group does not exceed (in fact, does not quite reach) that of the control group which was never reinforced in GB1. While absolute food pellet reductions in GBI produce faster second runway speeds than are found in appropriate nonshifted controls, this does not appear to be the case for relative food pellet reductions (Hamm, 1967). The present findings indicate that an absolute sucrose reduction may have the functional properties of a relative foodpellet reduction: there appears to be no RW 2 speed increment beyond that attributable to the removal of some demotivational factor. A series of studies is now in progress in the Houston laboratories which are exploring the effects of relative sucrose reductions in the double runway.

In further opposition to a frustration interpretation of an absolute sucrose reduction is the lack of an immediate increment in post-nonreinforcement behavior. The increase obtained is more suggestive of a gradual adjustment of performance to a new absolute reinforcement magnitude than of a rapid motivational energization.

\section{REFERENCES}

AMSEL, A. Partial reinforcement effects on vigor and persistence. In $K$. W. Spence and J. T. Spence (Eds.), Psycholosy of learning and motivation. New York: Academic Press, 1967.

AMSEL, A., \& ROUSSEL, J. Motivational properties of frustration: I. Effect on a running response of the addition of frustration to the motivational complex. Joumal of Experimental Psychology, 1952, 43, 363-368.

BARRETT, R. J., PEYSER, C. S., \& McHOSE, J. $H$. Effects of complete and incomplete reward reduction on a subsequent response. Psychonomic Science, 1965, 3, 277-278.

CLIFFORD, T., \& SCHINDELHEIM, R. H. The frustration effect as a function of runway length. Psychonomic Science, 1968, 10, 109-110.

HAMM, H. D. Perseveration and summation of the frustration effect. Journal of Experimental Psychology, 1967, 73, 196-203.

ISON, J. R. The role of reward magnitude in two process learning theory. Paper presented at the 1968 Chicago meeting of the Midwestern Psychological Association.

SEWARD, J. P., PEREBOOM, A.C., BUTLER, B., \& JONES, R. B. The role of prefeeding in an apparent frustration effect. Journal of Experimental Psy chology, 1957, 54, 445-450.

TUKEY, J. See B. J. Winer, Statistical principles in experimental design. New York: MoGraw-Hill, 1962.

\title{
An enlarged study of genotype and recovery of sex drive in male mice'
}

THOMAS E. McGILL, Williams College, Williamstown, Mass. 01267

This experiment replicated a previous study which showed that genotype affects the time required to recover sex drive in the male mouse. The present study involved larger samples and more genotypes than were used in the previous study. An orderly pattern of inheritance for recovery of sex drive was found.

In a previous study (McGill \& Blight, some evidence for genetic segregation of the trait. The purpose of the present study was to replicate that experiment and to extend it by enlarging the size of the samples and the number of genotypes tested.

\section{SUBJECTS}

The first two columns of Table 1 show the strains studied and the size of the samples. With the obvious exception of the inbred parent strains, reciprocal crosses were tested in all cases. Since there were no statistically significant differences between any pair of reciprocal crosses, the results are combined for those genotypes.

APPARATUS AND PROCEDURE

The apparatus and procedure were identical to those used in the previous experiment. In brief, sexually experienced males were tested after 14 days of sexual inactivity. The tests occurred during the dark phase of a reversed light-dark cycle. The animals were observed under normal room illumination, while they were enclosed in plastic cylinders $10 \mathrm{in}$. in diam and $20 \mathrm{in}$. in height. Females in hormone-induced estrus $^{2}$ were presented to the males and the time of ejaculation was noted. Then, using fresh, unmated females, periodic tests for recovery of sex drive were conducted until the male achieved a second ejaculation. The testing schedule is shown across the top of Table 1. Males remained caged in the plastic cylinders until the occurrence of the second ejaculation. Food and water were present within the cylinders between all tests following the third hour.

\section{RESULTS AND DISCUSSION}

Table 1 presents the results of this experiment. The last column indicates the median time of recovery of sex drive for the various genotypes. As in the previous experiment, the $\mathrm{C} 57 \mathrm{BL} / 6 \mathrm{~J}$ inbred strain required significantly longer ( $t$ test and $U$ test) to recover sex drive than did the DBA/ $2 J$ males or the F 1 males. The $F 1$ again did not differ significantly from the $\mathrm{DBA} / 2 \mathrm{~J}$.

In the previous experiment, C57BL $/ 6 \mathrm{~J}$ males and Backcross males (B6D2F 1 i $\mathrm{x}$ $\mathrm{C} 57 \mathrm{BL} / 6 \mathrm{~J}$ o) were rested and retested. The resulting distributions were quite similar to those found in the first test. The Spearman rank-difference test revealed no significant correlation between the results of Test 1 and Test 2 for the C57BL/6J group. However,

Table 1

Number of Male Mice of Different Genotypes Recovering Sex Drive at Different Intervals Following the Initial Ejaculation

\begin{tabular}{|c|c|c|c|c|c|c|c|c|c|c|c|c|c|c|c|c|c|}
\hline \multirow[b]{2}{*}{ Strains } & \multirow[b]{2}{*}{$\mathbf{N}$} & \multicolumn{15}{|c|}{ Hours to Recovery } & \multirow[b]{2}{*}{ Median } \\
\hline & & 1 & 2 & 3 & 6 & 12 & 24 & 36 & 48 & 72 & 96 & 120 & 144 & 168 & 192 & 216 & \\
\hline $\mathrm{DBA} / 2 \mathrm{~J}$ & 46 & 37 & 5 & 1 & 3 & & & & & & & & & & & & 1 \\
\hline $\mathrm{C} 57 \mathrm{BL} / 6 \mathrm{~J}$ & 56 & 1 & 0 & 1 & 3 & 4 & 3 & 3 & 5 & 12 & 10 & 3 & 5 & 3 & 1 & 2 & 72 \\
\hline F1 & 116 & 74 & 15 & 16 & 8 & 1 & 2 & & & & & & & & & & 1 \\
\hline $\mathrm{F} 2$ & 195 & 76 & 10 & 9 & 16 & 13 & 14 & 4 & 8 & 12 & 11 & 5 & 2 & 6 & 6 & 3 & 6 \\
\hline F $1 \times$ DBA & 130 & 77 & 9 & 6 & 3 & 5 & 8 & 1 & 4 & 3 & 5 & 4 & 4 & & & 1 & 1 \\
\hline$F 1 \times C 57$ & 130 & 28 & 7 & 6 & 7 & 14 & 14 & 7 & 10 & 8 & 5 & 11 & 5 & 4 & 2 & 2 & 24 \\
\hline
\end{tabular}


results for the Backcross group correlated +.72 , significant at the .01 level. This was interpreted as evidence for genetic segregation of the trait in the Backcross group.

A similar procedure was carried out for the C57BL/6J inbred males and the three segregating groups of the current experiment. The sample size in the replication was smaller than that shown in Table 1. Forty C57BL/6J males were retested, as were from 100 to 120 males in each of the three segregating populations. Once again, an insignificant correlation (t.12) was found for the C57BL/6J group. Correlations for the segregating populations ranged from +.20 to +.40 and were significant in all three cases. This finding supports our previous conclusion regarding genetic segregation in terms of the time required to recover sex drive in this particular test situation.

Unfortunately, the score distributions resulting from the tests of the present experiment do not meet the necessary criteria for further biometrical analyses (Bruell, 1962). This is true whether raw scores, or logarithms, or square roots of the raw scores are used. However, following an example given by Bruell (1962) who had similarly skewed distributions, Fig. 1 depicts the pattern of inheritance when median scores are plotted. As Fig. 1 shows, the median scores for the segregating populations (solid circles) fall very close to the points that are predicted (open circles) on the basis of the nonsegregating populations. (Formuli used in redicting the medians of the segregating populations shown in Fig. 1 are given in Bruell, 1962.)

While Fig. 1 clearly indicates dominance of the DBA/2J genotype in the determination of recovery of sex drive, it should be noted that the design of the experiment did not permit any overdominance present to reveal itself, since the first recovery test was not given until $1 \mathrm{~h}$ after the initial ejaculation. However, the distributions of scores for the DBA/2J and F1 groups in Table 1 would indicate that overdominance is probably not present for this particular cross for this trait, i.e., the mean recovery time for F1 is actually a bit higher than that for $\mathrm{DBA} / 2 \mathrm{~J}$.

The results of this experiment indicate a definite genetic effect on recovery of sex drive in the male mouse (Fig. 1). However, the results and conclusions are specific to the total experimental environment described above. It is doubtful that our test situation measures the minimum absolute refractory period following ejaculation. Consider the large range found for the C57BL/6J males as shown in Table 1. It seems unreasonable to suppose that these males vary so greatly in physiological recovery time. Furthermore, when the experiment was repeated for 40 of these

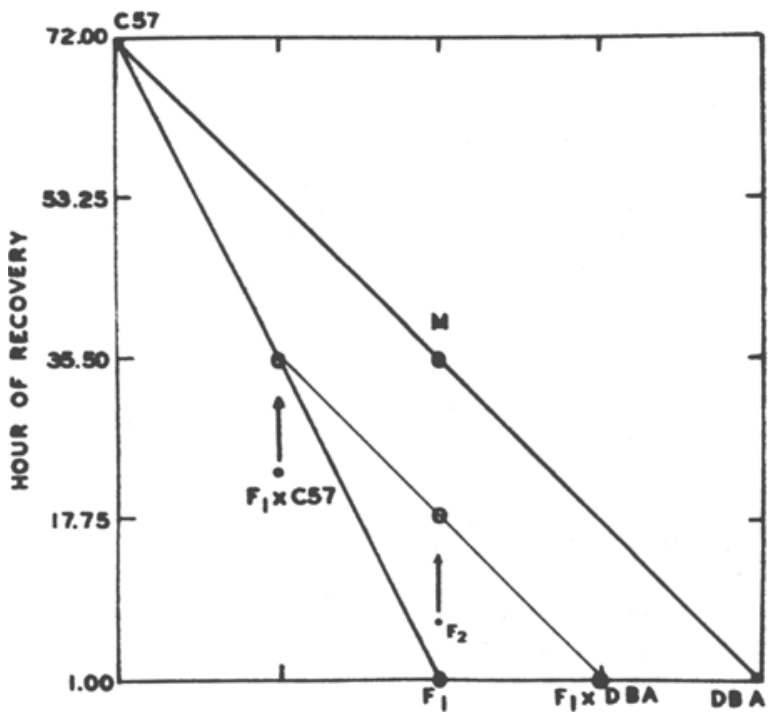

Fig. 1. Observed (solid circles) and expected (open circles) medions (see Bruell, 1962). $M=$ midparent.

males, the range and median were replicated almost exactly, but the test-retest correlation was not significant. Therefore, not only is there a large range of response in a group of these inbred males, but a single male, retested many times, would probably show similar variability. In discussing the results for this strain, McGill and Blight concluded, "Apparently the recovery of a C57BL/6J male is greatly influenced by transient, and unknown, environmental factors." This conclusion is supported by the lack of a significant correlation between the test-retest results of the present study. Ginsburg (1965) has listed a variety of behavioral and morphological measures for which the C57BL strain showed great variability. He concluded that this particular genotype is highly susceptible to environmental changes. This susceptibility can result in permanent changes such as increased skeletal variability, or in transient differences such as were observed in the present experiment.

\section{REFERENCES}

BRUELL, J. H. Dominance and segregation in the inheritance of quantitative behavior in mice. In E. L. Bliss (Ed.), Roots of behavior. New York, N.Y.: Harper \& Brothers, 1962.Pp. 48-67.

GINSBERG, B. E. Questions and group discussion. In F. A. Beach (Ed.), Sex and behwior. New York, N.Y.: John Wiley \& Sons, 1965.P. 87

McGILL, T. E., \& BLIGHT, W. C. Effects of genotype on the recovery of sex drive in the male mouse. Joumal of Comparative \& Physiological Psychology, 1963, 56, 887-888. NOTES

1. This research was supported by Research Grant 07495 from the Institute of General Medical Sciences, U.S. Public Health Service.

2. The hormone preparations were generousiy supplied by Dr. Preston L. Perlman, Schering Corporation, Bloomfield, New Jersey.

\section{Absence of change in some measures of cortical morphology in dark-reared adult rats'}

JUDITH A. R. BOAS, R. L. RAMSEY, A.H.
RIESEN, and J. P. WALKER, University of
California, Riverside, Calif. 92502

The frontal and visual cortices of 200-day-old rats were microscopically examined after staining with Golgi-Cox.
Measures included cellular density, total thickness of cortex, thickness of Layers 1 and 3 , and nuclear volumes in three layers. No differences between dark- and lightreared $S s$ were found within brain regions. The data are interpreted in terms of current literature on cortical effects of sensory deprivation. 